\title{
Os processos comunicacionais em rede e a emergência do dispositivo conexial
}

\author{
Moisés Sbardelotto ${ }^{1}$
}

\begin{abstract}
Resumo: Nos mais diversos âmbitos da internet, a sociedade em geral fala sobre o socius, retrabalhando e ressignificando os diversos sentidos sociais, atualizando-os a novos interagentes sociais e a públicos ainda maiores. Em rede, essa construção de sentido sobre o socius se dá mediante um dispositivo digital próprio. Este artigo resgata algumas reflexões sobre o conceito de dispositivo, para, em um segundo momento, relacioná-lo com o contexto do ambiente digital, a partir das ideias de interface, protocolo e reconexão. Mediante uma reflexão teórico-metodológica, propõe-se, a partir dessa relação, o conceito de dispositivo conexial, que busca articular os âmbitos social, tecnológico e simbólico dos processos comunicacionais em rede.
\end{abstract}

Palavras-chave: Dispositivo conexial, interface, protocolo, reconexão; internet.

\begin{abstract}
In various areas of the Internet, society in general talks about the socius, reworking and resignifying the various social meanings, updating them to new social inter-agents and even to greater publics. In social networks, this construction of meanings on the socius occurs by a specific digital dispositif. This article reflects upon the concept of dispositif, to relate it, in a second moment, with the context of the digital environment, from the ideas of interface, protocol and reconnection. Through a theoretical and methodological reflection, it proposes, from such a relationship, the concept of connectial dispositif, which tries to articulate the social, technological, and symbolic ambits of the networked communication processes.
\end{abstract}

Keywords: Connectial dispositif, interface, protocol, reconnection, internet.

As práticas sociais no ambiente online, a partir de lógicas midiáticas, complexificam hoje o fenômeno social. Formam-se novas modalidades de percepção e de expressão do socius em novos ambientes comunicacionais, como as plataformas sociodigitais, ou seja, os padrões comunicacionais online caracterizados por interfaces e protocolos multimodais. Tais plataformas envolvem, ao mesmo tempo, softwares, sites e aplicativos próprios, todos interconectáveis, que se inter-relacionam com as demais plataformas e podem ser acionados mediante os mais diversos aparatos digitais (computador, celular, tablete), a eles se ajustando de modo interdependente. Nelas, os construtos sociais passam a circular, fluir, deslocar-se por meio de uma ação não apenas do âmbito da "produção" industrial-midiática, mas também mediante uma ação comunicacional dos inúmeros usuários conectados.

\footnotetext{
${ }^{1}$ Doutor e mestre em Ciências da Comunicação pela Universidade do Vale do Rio dos Sinos (Unisinos), com estágio doutoral na Università di Roma "La Sapienza", Itália. Graduado em Comunicação Social - Jornalismo pela Universidade Federal do Rio Grande do Sul (UFRGS). E-mail: m.sbar@yahoo.com.br. 
Em plataformas como Facebook, Twitter e Instagram, instituições sociais e sociedade em geral encontram-se agora marcadas por novas possibilidades de construção de sentido, em termos de acesso, criação, armazenamento, gestão, distribuição e consumo de informações - indo muito além da ação tradicional da "grande mídia", entendida como as corporações midiáticas, e muito além das ações institucionais tradicionais voltadas à comunicação (SBARDELOTTO, 2016). Em tal processo sociocomunicacional, dá-se o advento de um novo tipo de "gestão" do social, que passa, agora, pela mediação de novos agentes midiáticos, que não substituem, mas se articulam aos agentes tradicionais.

Nos mais diversos âmbitos da internet, portanto, a sociedade em geral fala sobre o socius, retrabalhando, ressignificando, ressemantizando os diversos sentidos sociais, atualizando-os a novos interagentes sociais e a públicos ainda maiores, em uma trama complexa. Em suas interrelações, tais ações acionam um processo de circulação comunicacional, por meio de lógicas e dinâmicas midiáticas. A sociedade fala sobre e faz algo com o social, para além da oferta disponível na internet por parte da grande mídia ou das instituições sociais tradicionais. Construtos sociais vão sendo ofertados não por um polo fixo de produção, mas ofertadosrecebidos constante e simultaneamente pelos mais diversos interagentes sociais (indivíduos, grupos e instituições), para além de qualquer controle simbólico. A circulação, assim, torna-se um dispositivo organizador da comunicação (FAUSTO NETO, 2013), dando forma às ações comunicacionais.

$\mathrm{Na}$ internet, emergem redes comunicacionais online, ou seja, as diversas matrizes de comunicabilidade em interconexões sociodigitais, envolvendo processos comunicacionais transversais que se estabelecem a partir conexões digitais, nas e para além das plataformas sociodigitais. Nelas, os diversos indivíduos, grupos e instituições, mediante as mais diversas “conexões de conexões”, vão constituindo competências de organização das possibilidades de construção de sentido social sobre o socius, mediante um dispositivo digital próprio, que aqui chamamos de conexial.

Neste artigo, portanto, resgatamos algumas reflexões sobre o conceito de dispositivo, para, em um segundo momento, relacioná-lo com o contexto do ambiente digital, a partir das ideias de interface, protocolo e reconexão. Mediante uma reflexão teórico-metodológica, propomos, a partir de tal articulação, o conceito de dispositivo conexial, que busca articular os âmbitos social, tecnológico e simbólico dos processos comunicacionais em rede. 


\section{O conceito de dispositivo: um breve resgate}

A circulação em redes comunicacionais online e a própria estrutura instável de tais redes se concretiza naquilo que Ferreira (2013, p. 147, trad. nossa) denomina de dispositivos midiáticos, isto é, nem o meio nem a mensagem, mas "um lugar de inscrição que se transforma em operador de novas condições de produção e de recepção e, ao mesmo tempo, passagem e meio". Trata-se, segundo o autor, de uma "abstração do conjunto de relações" das mediações midiáticas que, neste caso, se estabelecem nas redes comunicacionais online, envolvendo "as diversas economias (políticas, culturais, institucionais de diversos campos, afetivas, intelectuais etc.) presentes nas interações" midiáticas em sociedade (idem, trad. nossa).

O conceito de "dispositivo", como eixo analítico especialmente em Ciências Humanas, remonta a Foucault, que o definiu como

\footnotetext{
um conjunto decididamente heterogêneo que engloba discursos, instituições, organizações arquitetônicas, decisões regulamentares, leis, medidas administrativas, enunciados científicos, proposições filosóficas, morais, filantrópicas. Em suma, o dito e o não dito são os elementos do dispositivo. O dispositivo é a rede que se pode tecer entre estes elementos (FOUCAULT, 2000, p. 244, grifo nosso).
}

Não cabe aqui uma genealogia do conceito na filosofia foucaultiana, mas, resgatando sua relevância nos estudos socioantropológicos, nos apropriamos das suas ideias centrais, como a heterogeneidade e a interconexão dos elementos que compõem um dispositivo, que não estão dados de antemão, mas podem ser tecidos pelo observador. No caso comunicacional, a noção de dispositivo nos ajuda a compreender as processualidades das redes comunicacionais online, que “incorporam vários processos circulares de comunicação, incluindo os receptores de diversos níveis, operando em redes" (FERREIRA, 2012, p. 256, trad. nossa). Por isso, perceber as redes comunicacionais online como dispositivos midiáticos é poder compreender a "organização estruturada de meios materiais, tecnológicos, simbólicos e relacionais, naturais e artificiais, que tipificam, a partir de suas características próprias, os comportamentos e as condutas sociais, cognitivas, afetivas dos sujeitos" (PERAYA, 2002, p. 29).

Colocando o foco em tais redes, é preciso aproximar o conceito de dispositivo das processualidades que se dão nas interações para a circulação. Para isso, nos apropriamos das reflexões de Peraya (2002), Ferreira (2006) e Braga (2011), que propõem conceituações que nos ajudam a especificar as contribuições do conceito para o estudo da circulação em rede. 
Braga (2011, p. 5) sugere um conceito mais geral, "dispositivos interacionais”, entendidos como a articulação de "determinadas matrizes interacionais e modos práticos compartilhados para fazer avançar a interação". Tais dispositivos são produzidos em circunstâncias históricas e em contextos específicos de interação, sendo "modulados pelos contextos e processos institucionais específicos em cujo ambiente ou referência se desenvolvem" (ibid., p. 6). Entendido basicamente como um abrangente, heterogêneo e complexo "sistema de relações", o central do conceito é entendê-lo como "modos de fazer socialmente produzidos e tornados disponíveis" e que "se organizam social e praticamente como base para comunicação entre participantes" (ibid., p. 911).

Peraya (2002) e Ferreira (2006) aproximam a lente de análise, defendendo, ambos, relações triádicas no interior dos dispositivos. Peraya (2002) analisa o conjunto de interações promovidas pelas mídias "entre os universos técnico, semiótico e ainda social ou relacional", chamando-o de "dispositivo tecno-semiopragmático" (p. 29). Já Ferreira (2006, p. 138) analisa os dispositivos midiáticos como "um lugar de interação entre três universos: uma tecnologia, um sistema de relações sociais e um sistema de representações”. Em publicação mais recente, o autor fala de relações entre três matrizes: "A técnica e a tecnologia; as interações; e a semio-linguísticadiscursiva", interações estas que "não são de determinação unívoca e linear. É uma relação matricial, de mútuas determinações" (ibid., 2012a, p. 256, trad. nossa).

Cremos que tal tríade - social, tecnológica, simbólica - é de grande relevância para a análise dos fenômenos comunicacionais, pois nos ajuda a superar determinismos de qualquer ordem. $\mathrm{Na}$ articulação complexa, inter-relacional e retroativa entre tais polos, encontramos a distinguibilidade das ações em jogo, mas, ao mesmo tempo, a sua inseparabilidade como fenômeno (MORIN, 2008). É a tensão entre as polaridades da tríade que merecem análise, as complexas inter-relações entre processos sociais, tecnológicos e simbólicos. Articulados por interrelações complexas, trata-se de processos dialógicos e recursivos, isto é, nenhum dos três polos pode ser concebido fora da inter-relação complementar, concorrente e antagônica com os outros dois, pois é nela que ele ganha sentido e "força".

Assim, parece-nos central retomar as características de heterogeneidade, interconectividade e matricialidade triádica dos dispositivos midiáticos. O dispositivo emerge aí como "sistema abstrato descritível" (BRAGA, 2013, p. 168) a partir das inferências do 
observador, que, contudo, são articuladas a partir de relações e processos empiricamente identificáveis em um ambiente comunicacional específico.

Portanto, o dispositivo não é um "lá fora" em relação às práticas comunicacionais, sendo impossível separar, "de um lado, os seres viventes [...] e, de outro, os dispositivos em que eles são incessantemente capturados" (AGAMBEN, 2006, p. 21, trad. nossa). O social também se inscreve nos dispositivos, e só é possível falar, em relação ao dispositivo, da "capacidade de capturar, orientar, determinar, interceptar, modelar, controlar e assegurar os gestos, as condutas, as opiniões e os discursos" (ibid., p. 21, trad. nossa) se compreendermos que a heterogeneidade do dispositivo pressupõe também a interconexão entre os interagentes que o compõem. Portanto, não são capacidades exclusivas do dispositivo, mas sim capacidades compartilhadas pelos interagentes presentes no interior de um dispositivo circunscrito e deste com o seu contexto mais amplo.

\section{A emergência do dispositivo conexial}

Indo além de uma análise meramente sociológica, tecnológica ou computacional das chamadas "redes sociais" ou das "redes digitais", reconhecemos que a essência das redes não está na rede, mas em seus complexos modos de apropriação, organização e reconfiguração sóciotecno-simbólicas. Se a midiatização produz novas formas de construção de sentido na sociedade, esta está diretamente vinculada às lógicas dos fluxos, "tendo como fim a produção de uma nova forma de vínculo social, no caso as estruturas de conexões" (FAUSTO NETO, 2005, p.3, grifo nosso) entre os processos midiáticos, e entre estes e a sociedade. Por isso é necessário estar atento aos padrões das interconexões que ocorrem em redes comunicacionais online específicas.

Aqui, ao sistema sócio-técnico-simbólico heterogêneo que possibilita a conexão digital e organiza a comunicação entre os interagentes em rede chamamos de dispositivo conexial. Não se trata apenas de um dispositivo de conexões meramente tecnológicas (cabos, fios, hubs), mas sim de um sistema de relações nas redes comunicacionais online entre interagentes humanos, tecnológicos e simbólicos. Na medida em que a mediação em jogo nas redes comunicacionais online "é ato, muitos dos quais são socialmente reconhecidos, incorporam-se novos objetos às materialidades e novos imaginários, muitos dos quais são socialmente compartilhados, espaços centrais para a compreensão dos dispositivos" (FERREIRA \& DAIBERT, 2012, p. 85, grifo 
nosso, trad. nossa). Nesse sentido, o dispositivo emergente em rede envolve uma inter-relação complexa entre os âmbitos social, tecnológico e simbólico, que se organizam interretroativamente.

Esse complexo de inter-relações triádicas que constituem o dispositivo conexial não está dado de antemão, mas emerge a partir de processualidades características das redes comunicacionais online. Seja no Facebook, seja no Twitter, seja no Instagram, as interações só são possíveis porque articulam, por sua vez, lógicas e dinâmicas sociais, tecnológicas e simbólicas. Cruzando os aspectos social, tecnológico e simbólico, buscamos complexificar a nossa compreensão de dispositivo conexial a partir das inter-relações entre as interfaces presentes nas plataformas sociodigitais, os protocolos que neles emergem e as reconexões que caracterizam os processos midiáticos digitais, que atuam, respectivamente, como regulações, regras $e$ regularidades (CINGOLANI, 2015) das redes comunicacionais online.

\section{Processos tecnossimbólicos: a interface}

Em redes comunicacionais online, percebemos que indivíduos, grupos e instituições se apropriam de determinadas plataformas técnicas que lhes permitem constituir conexões com a sociedade mais ampla. Facebook, Twitter e Instagram, por exemplo, oferecem à sociedade uma determinada forma de conexão (páginas, contas, perfis, posts, comentários, "curtidas" etc.), que não é neutra nem automática, mas solicita a intervenção social para a sua constituição.

As interfaces, primeiramente, são o "lugar" das interações em plataformas sociodigitais. Elas são acessíveis por meio de artefatos maquínicos (computador, tablete, celular, tela, teclado, mouse) e elementos simbólicos presentes na linguagem digital (menus, ambientes, links). Com elas, é possível agir e interagir no ambiente digital: as interfaces são, assim, um ambiente de contato entre tecnologias e usuários, ou entre usuários mediados por redes digitais, que possibilitam a circulação. Trata-se, portanto, de uma relação complexa entre processos tecnossimbólicos, que, interretroativamente, relacionam lógicas e dinâmicas tecnológicas e simbólicas.

Mesmo que as possibilidades de interação sejam (de)limitadas pelas plataformas, o usuário ainda pode ultrapassá-las e buscar outras possibilidades, seja abusando do sistema - não correspondendo às suas propostas - ou então abandonando-o. Desse modo, há um desequilíbrio e 
uma dialética entre como o sistema é pensado e projetado, e como ele é usado na prática pelos usuários. Pois nenhum sistema funciona ou é utilizado conforme o programador previu. Isto é, o sistema "cria" o seu próprio usuário, assim como o usuário, mediante seus usos e apropriações, também ajuda a "criar" o seu próprio sistema comunicacional.

A superfície técnica das interfaces é, primeiramente, programada e padronizada pelas próprias plataformas, e as interações que aí se estabelecem com os usuários se dão a partir das limitações e potencialidades possibilitadas por essa superfície. Mas, depois, tais funcionalidades são complexificadas por novas superfícies simbólicas construídas pela sociedade e voltada a usos específicos, que são ressignificados nas interações com os usuários. Aí se manifesta o processo tecnossimbólico antes referido, que é interretroativo. A interface é, ao mesmo tempo, uma área de circunscrição, por parte dos programadores, e uma área de escolha, por parte dos usuários, que une e separa concomitantemente as plataformas e os interagentes, que se põem em negociação e em tensão mediante as interfaces.

O que caracteriza a interface de tais plataformas é um programa regulador das interações por elas estabelecido e reconstruído junto aos diversos interagentes. As interfaces operam mediante uma lógica de delimitação das redes, pois não eliminam as "fronteiras" entre os interagentes, mas promovem, ao contrário, "uma contínua diferenciação das partes e dos limites" (BRUNO, 2001, p. 199, grifo nosso) que os distinguem.

Assim, a interface se constitui como um locus organizador das interações e conexões em redes comunicacionais online. Seus elementos e sua composição geral buscam indicar ao usuário as especificidades comunicacionais daquele ambiente, delimitando-o. O usuário, por sua vez, pode agir com tal ambiente a partir de sua interface, estabelecendo a interação mediante suas regulações. Em suma, as interfaces são constantemente ressignificadas e recontextualizadas de acordo com os interesses da página em sua relação com os interagentes e mediante essa mesma relação. No ambiente digital, dada sua multiplexidade, os diversos interagentes só podem constituir suas conexões "interfaciados", mediados por interfaces. Portanto, as interfaces são a síntese comunicacional das regulações em torno das interações e conexões sociodigitais. As interfaces, como redes de mediação, são o modo regulado de agir em redes comunicacionais online. 
A regulação desses processos, justamente para que não ocorra nem a desestabilização nem o enrijecimento da plataforma, mediante usos desregulados por parte dos usuários ou o bloqueio desses usos por parte da plataforma, ocorre por meio de protocolos.

\section{Processos sociotécnicos: o protocolo}

Não é apenas a interface que delimita e dinamiza as práticas sociais nas plataformas sociodigitais. Há também a emergência de uma série de condições de possibilidade a partir da interação social, constituídas entre os próprios usuários, para além dos limites e possibilidades oferecidos pelas plataformas. Existe uma série de regras, flexíveis e mutáveis (termos e políticas de uso, normas e padrões sobre conteúdos e privacidade, "postar", "curtir", "comentar", "compartilhar" etc.), que garantem as conexões sociodigitais e as interações comunicacionais entre os vários interagentes.

Tais regras - entendidas como protocolos - emergem nas interações e organizam o fluxo circulatório, permitindo certas coisas e impedindo outras, mediante um trabalho de tensão e negociação entre plataformas e interagentes. Nesse sentido, os protocolos geram e são gerados por processos sociotécnicos de organização das conexões, que, interretroativamente, relacionam lógicas e dinâmicas sociais e tecnológicas, visando condicionar as modalidades de ação - embora sempre com escapes e rupturas por parte da invenção sociocultural. Sem protocolo, não há conexão e, consequentemente, não há rede (GALLOWAY, 2004). Ignorar os protocolos significa obstaculizar a conexão e, portanto, a comunicação.

Assim, é possível perceber modalidades de protocolo que regulam as formas de interação, os usos possíveis e permitidos das plataformas, ou as modalidades de gestão e manipulação dos símbolos (textos, imagens e vídeos) disponibilizados pelas páginas. Isto é, "a delimitação das fronteiras dos quadros das interações em que os seres humanos se envolvem não preexiste ao desenrolar da própria interação, mas depende de um trabalho de negociação que os interactantes realizam em comum" (RODRIGUES, 2011, p. 272), sob a forma de protocolos. Trata-se da emergência de sistemas organizadores das interações decorrentes da própria prática interacional, "de sistemas de cooperação padronizados para garantir a estabilidade dos processos - mesmo em situações que enfatizam a liberdade da interação, a ausência de hierarquias, a horizontalidade" (BRAGA, 2013, p. 168). 
Os protocolos, portanto, vão surgindo e se desdobrando na própria ação de interagir - seja entre o sistema e os usuários, seja entre os próprios usuários -, operando segundo uma lógica de condicionamento das redes comunicacionais online, possibilitando a constituição de vínculos e de conexões entre os interagentes mediante interfaces específicas, sob certas condições, em uma “delicada dança entre controle e liberdade" (GALLOWAY, 2004, p. 75, trad. nossa). Eles se constituem na relação entre as interfaces e os usos sociais, e também vão surgindo ou se desdobrando na própria ação de interagir - seja entre o sistema e os usuários, seja entre os próprios usuários.

Vemos que as escolhas do interagente funcionam em função dos protocolos das plataformas e das páginas, e, por sua vez, as plataformas e as páginas funcionam em função dos protocolos dos seus "funcionários", ou seja, dos interagentes. Estes funcionários "trabalham" para as plataformas (ou para as páginas) em seu próprio interior, realizando usos previstos (e assim gerando matéria-prima comunicacional que realimenta o fluxo circulatório) ou imprevistos (que potencialmente podem levar a aprimoramentos dos sistemas e dos próprios protocolos). Dessa forma, o interagente crê estar utilizando as plataformas ou as páginas como "meio" para a sua construção de sentido em rede (seja em recepção, seja em produção), e as plataformas e as páginas creem estar utilizando o interagente como "meio" para realimentar seus processos internos. Contudo, o que temos é um processo coevolutivo e indeterminado, em que plataformas e interagentes (páginas ou indivíduos) interretroagem reciprocamente mediante protocolos.

Por isso, é preciso perceber que os protocolos não são neutros nem intra nem extraplataformicamente, pois são portadores de valores e fonte de significações sociais para os interagentes comunicacionais. Ou seja, a esfera tecnossimbólica (as interfaces aqui analisadas) também são constituídas socialmente (mediante protocolos sociotécnicos). Dessa forma, as plataformas estruturam as práticas sociais em rede, e estas, de acordo com usos específicos, atribuem sentidos singulares às plataformas provenientes do âmbito social: dessa inter-relação, emergem os protocolos como "interface das interfaces" sociotécnicas. Se o poder é uma "ação sobre ações" (FOUCAULT, 1995, p. 243), os protocolos se constituem como redes de poder, como uma ação de condicionamento das ações comunicacionais possíveis, constituindo um modo regrado de agir em redes comunicacionais online.

Os protocolos, portanto, operam como regras explícitas, implícitas e convencionadas que indicam condições e possibilidades aos interagentes em suas ações comunicacionais: existe uma 
protocolaridade que subjaz às interações, delimitadas tanto pelas plataformas, quanto pelas páginas e contas em seu interior, quanto ainda pelos interagentes: não há um único "sujeito de poder protocolar" nas redes, pois tal processo sociotécnico é relacional e coevolutivo. Se há "controle" nas redes, ele é dialógico, composto por mecanismos de controle e contracontrole. O protocolo, afirma Galloway (2004, p. 82, trad. nossa), é anti-hierárquico e antiautoritário.

Manifesta-se, desse modo, um fluxo circulatório organizado a partir de ações protocolares comuns, que visam a condicionar as conexões sociodigitais e as interações comunicacionais. $\mathrm{O}$ dispositivo conexial, contudo, não se resume a essa dupla mediação interfaces-protocolos. As interfaces são acionadas, mediante protocolos, para o desenvolvimento de determinadas práticas sociais, neste caso, a explicitação pública de saberes-fazeres midiático-comunicacionais, por meio de reconexões em redes comunicacionais online.

\section{Processos sociossimbólicos: a reconexão}

O ambiente digital possibilita uma complexa rede de interações comunicacionais, em que plataformas como Facebook e Twitter passam a ser compartilhadas midiaticamente por interagentes sociais para a construção de sentido mediante textos, fotos, áudios, vídeos. Tais conexões, por sua vez, se inter-relacionam com operações de computação (MORIN, 1999), entendidas como a ação de computar, de tratar símbolos, mediante percepção, cognição e expressão em rede. Trata-se, entretanto, de uma computação de terceira ordem, em que um conteúdo simbólico é construído publicamente por um interagente (1), recebido e reconhecido por outro interagente em conexão (2) e, potencialmente, reconstruído para outros interagentes mediante novas conexões (3). Assim, o próprio socius vai sendo ressignificado a partir dos mais diversos pontos de vista da sociedade, que se publicizam e se visibilizam midiaticamente.

Em plataformas sociodigitais, os diversos interagentes - individuais ou institucionais - podem produzir uma "palavra pública" e também agir publicamente sobre o fenômeno social. Eles encontram formas de (re)dizer e (re)fazer discursos e símbolos, mediante imagens, textos, vídeos. Ocorre, assim, uma experimentação social, que caracteriza uma prática específica das sociedades em midiatização. A reconexão, portanto, é a ação comunicacional sobre interfaces e protocolos (mediante conexão e computação) e para além deles (mediante novas conexões e novas 
computações), alimentando a circulação comunicacional. Trata-se de um processo sociossimbólico, que, inter-retroativamente, relaciona lógicas e dinâmicas sociais e simbólicas.

A reconexão atua como processo "condensador semiótico" (LOTMAN, 1996). Nele, o símbolo atravessa "o espessor das culturas", mantendo a sua "essência invariante", é reconectado com outros símbolos, interagentes e contextos socioculturais, e também "se transforma sob a sua influência e, por sua vez, o[s] transforma" (ibid., p. 146, trad. e grifo nossos). Em seu nível simbólico, as reconexões operam uma redução da complexidade social mediante sua "dimensão organizadora do comum" (SODRÉ, 2014, p. 275). Em seu nível social, as reconexões conectam as instâncias de produção e recepção, em sua comutabilidade, e, ao conectarem-nas, fazem surgir as diferenças em termos de ação sociossimbólica.

As reconexões, portanto, articulam-se em torno de lógicas de condensação, em um triplo sentido: 1) "liquefazendo", "diluindo" discursos e símbolos sociais na constante descontextualização dos conteúdos em rede; 2) "juntando", "amontoando" novamente tais discursos e símbolos mediante recombinação com outros interagentes, discursos, símbolos e contextos; e 3) "engrossando" o fluxo circulatório com tais reconstruções, dinamizando-o.

Mediante reconexões, os interagentes produzem um conhecimento novo e emergente de suas trocas comunicacionais, em uma coprodução de sentido, gerando um "cômputo" muito mais complexo do que algo meramente humano e/ou tecnológico, envolvendo também outros interagentes e contextos comunicacionais. Por isso, as reconexões são "conexões de conexões" em rede, "ultraconexões", "conexões novas", não por surgirem ab ovo, mas por emergirem de modo complexo na conjuntura de uma interação singular em um contexto específico, na interrelação com interfaces e protocolos, indo além do já dado em termos sociais, tecnológicos e simbólicos. As reconexões revelam a experimentação social em processos de circulação comunicacional, em que é possível partir de algo já dado e inventar comunicacionalmente, chegando a algo novo (in + venire) por meio de práticas conexiais, que se somam e complexificam as práticas tradicionais de construção social de sentido.

Vemos, assim, que o sentido se constrói em circulação, “preso em feixes de relações - situação que afastaria a interação das possibilidades de equilíbrio e de linearidade. Em lugar de sentidos atribuídos, desponta a indeterminação" (FAUSTO NETO, 2013, p. 45, grifo nosso). As reconexões, como redes de conexão, explicitam o modo regular de ação em redes comunicacionais online. Sem ação de conexão, não há rede. 
Analisados tais processos tecnossimbólicos, sociotécnicos e sociossimbólicos em suas especificidades, podemos agora articulá-los reflexivamente como dispositivo conexial.

\section{Dispondo as conexões do dispositivo conexial}

A partir do acionamento comunicacional de uma dada tecnologia para a constituição de interações em rede (interface), negociada e agenciada dentro de condições específicas (protocolos), mediante o que a sociedade produz simbolicamente em rede sobre e a partir dessa inter-relação (reconexão), instauram-se complexas conexões, que geram matrizes de interação na internet, que por sua vez promovem e permitem a gênese do socius.

As interfaces, em sua lógica de delimitação, atuam como redes de mediação, que constituem o modo regulado de ação em redes comunicacionais online. Para que as interfaces sejam acionadas comunicacionalmente, os interagentes, em relação a elas e aos demais interagentes, estabelecem protocolos, que atuam como redes de poder, em uma lógica de condicionamento, constituindo um modo regrado de agir em redes comunicacionais online. Articulando interfaces e protocolos, os interagentes operam reconexões em redes comunicacionais online, ou seja, modos regulares de ação no ambiente digital, que atuam como redes de conexão em uma lógica de condensação.

Esquematicamente, podemos relacionar tais características das interfaces, protocolos e reconexões em seus diversos tipos de processualidade, conectividade, logicidade e dinamicidade que os compõem e que, por sua vez, organizam as redes comunicacionais online (Tab. 1). 
Tabela 1 - Características das interfaces, protocolos e reconexões em redes comunicacionais online

\begin{tabular}{|l|c|c|c|}
\hline & Interfaces & Protocolos & Reconexões \\
\hline Processualidade & Tecnossimbólica & Sociotécnica & Sociossimbólica \\
\hline Conectividade & Redes de mediação & Redes de poder & Redes de conexão \\
\hline Logicidade & Delimitação & Condicionamento & Condensação \\
\hline Dinamicidade & $\begin{array}{c}\text { Modo regulado de } \\
\text { ação }\end{array}$ & $\begin{array}{c}\text { Modo regrado de } \\
\text { ação }\end{array}$ & $\begin{array}{c}\text { Modo regular de } \\
\text { ação }\end{array}$ \\
\hline
\end{tabular}

Fonte: Elaborado pelo autor.

Esse complexo de inter-relações entre interfaces, protocolos e reconexões, em suas características diversas e em seus diversos tipos de emergência em redes comunicacionais online, constitui aquilo que chamamos de dispositivo conexial. Ele organiza os processos tecnossimbólicos, sociotécnicos e sociossimbólicos que delimitam, condicionam e condensam, respectivamente, as práticas sociais e a reconstrução do socius em redes comunicacionais online, operando como regulações, regras e regularidades em torno das conexões.

Trata-se de um dispositivo conexial porque a "essência" de toda rede é precisamente a conectividade (KERCKHOVE, 1998). A internet é "o meio [media] conectado por excelência", explicitando uma condição natural da interação humana (ibid., p.25, trad. e grifo nossos). Não se trata, portanto, de um dispositivo de conexões meramente tecnológicas (cabos, fios, hubs), mas sim de um sistema de relações digitais entre interagentes humanos, tecnológicos e simbólicos. Se a rede não é um produto acabado e delimitado, mas um observável que opera dentro de determinadas lógicas e dinâmicas, estas são continuamente reinventadas e reconstruídas pelos desdobramentos de processos sociais, tecnológicos e simbólicos que constituem o dispositivo conexial.

Em síntese, como indica a Figura 1, o dispositivo conexial emerge como um sistema sócio-tecno-simbólico heterogêneo, articulando relações matriciais triádicas (triângulos) em movimentos interretroativos dinâmicos (círculos). 
Figura 1 - Diagrama do dispositivo conexial

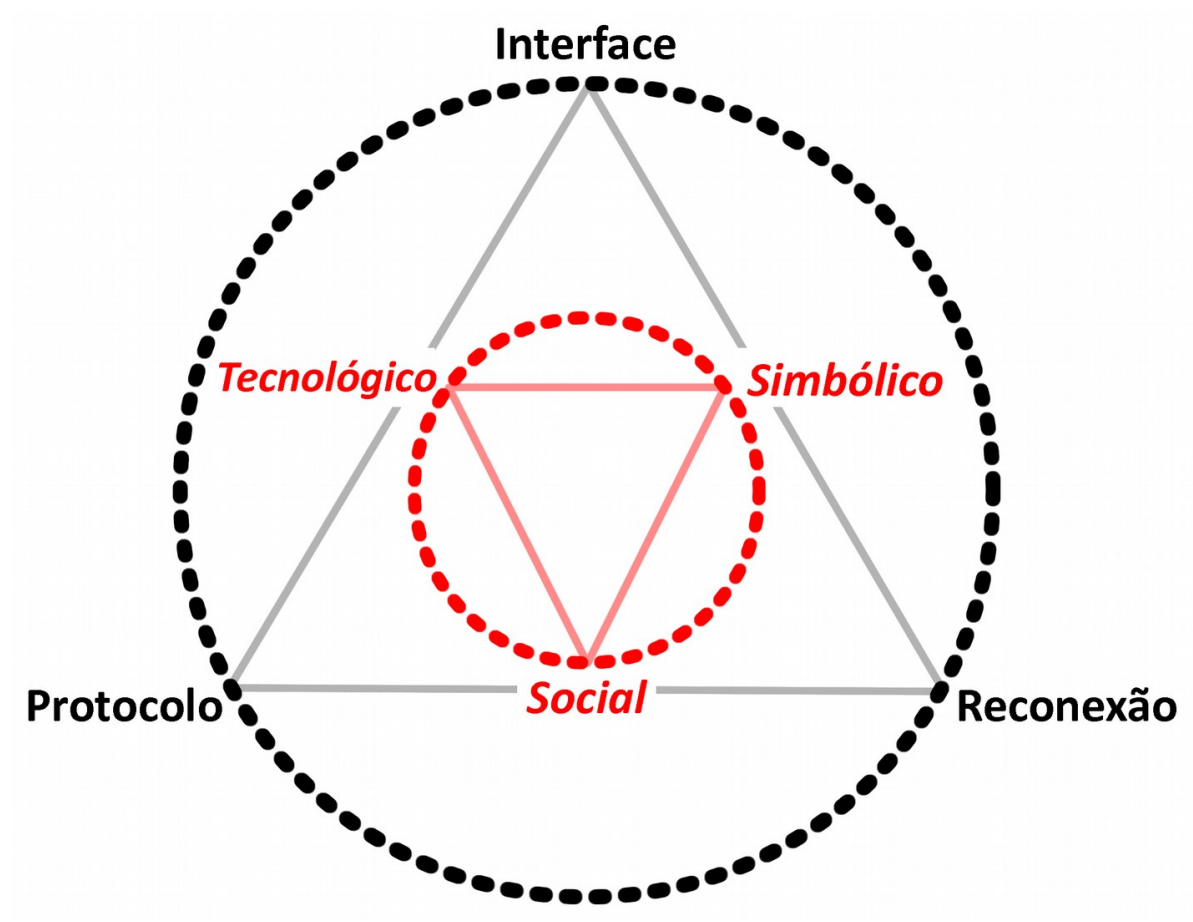

Fonte: Elaborado pelo autor.

A articulação menor atua como lógica geradora da articulação matricial maior, também triádica e dinâmica, formada por inter-relações entre processos tecnológicos e simbólicos (interface), entre processos tecnológicos e sociais (protocolo), e processos sociais e simbólicos (reconexão). É esse complexo sistêmico, portanto, que possibilita a conexão digital e organiza a comunicação entre os interagentes em redes comunicacionais online, catalisando as práticas sociomidiáticas no fluxo circulatório das plataformas sociodigitais.

A dinâmica da relação entre interfaces, protocolos e reconexões se baseia no processo flexível e criativo pelo qual interagentes, tecnologias e símbolos interagem nas plataformas sociodigitais, materializando conexões mediante seu exercício de agenciamento local, estabelecendo processos midiáticos em redes comunicacionais online. As interfaces estabelecem e possibilitam a emergência de determinados protocolos e de modalidades específicas de reconexão; os protocolos, por sua vez, coevoluindo de forma complexa, demandam e possibilitam a emergência de novas interfaces e de novas reconexões. Já as reconexões se desdobram e se atualizam sempre em interfaces específicas e mediante protocolos locais. De modo geral, podemos afirmar que toda ação social é mediada tecnologicamente, e atravessa e é atravessada 
por construções simbólicas; toda tecnologia é constituída socialmente e encarna simbologias; e toda prática simbólica é construída socialmente por meio de técnicas e tecnologias.

$\mathrm{Na}$ interface entre a heteronomia institucional e a autonomia social, o dispositivo interacional permite a constituição de processos de gênese de sentido, que dinamizam o fluxo circulatório em redes comunicacionais online. Sem tal dispositivo, a circulação não ocorreria e não haveria qualquer tipo de organização na complexidade das redes comunicacionais online; em suma, não teríamos tais redes. O dispositivo conexial é o princípio de organização das redes comunicacionais online, atuando como um ordenador de dupla ordem: ordena as conexões, estabelecendo possibilidades de interação; e dá ordens aos interagentes em rede, estabelecendo limites e possibilidades para as conexões (cf. MORIN, 2008). Trata-se de um aparelho de organização da comunicação, que apresenta um "caráter dependente (com relação ao homem) e imperativo (com relação à máquina)" (ibid., p.295), ou seja, emancipa e domina ao mesmo tempo.

\section{Conclusões}

A partir do acionamento comunicacional de uma dada tecnologia para a constituição de interações em rede (interface), negociada e agenciada dentro de condições específicas (protocolos), mediante o que a sociedade produz simbolicamente em rede sobre e a partir dessa inter-relação (reconexão), instauram-se complexas conexões, que geram matrizes sociais de interação na internet, que por sua vez promovem e permitem a gênese do socius. Delimitando, condicionando e condensando o fluxo circulatório, o dispositivo conexial, como um complexo de inter-relações entre interfaces, protocolos e reconexões, organiza os processos sociomidiáticos, transformando "uma diversidade separada em uma forma global" (MORIN, 2008, p. 164).

Pelo fato de as redes serem uma "estrutura composta de elementos em interação, de interconexão instável e cuja variabilidade obedece a alguma regra de funcionamento" (MUSSO, 2004, p. 31), o dispositivo conexial nos ajuda a entender os padrões que caracterizam as redes, que surgem a partir de complexos modos de reconfiguração por parte da sociedade. Ações locais de interação em experimentação constituem determinadas matrizes comunicacionais específicas e flexíveis que caracterizam um dispositivo, e este, por sua vez, condiciona e molda aquelas ações, que reconstitui o próprio dispositivo. O dispositivo é constituído e também modificado sociocomunicacionalmente. 
Em suma, o dispositivos conexial dispõe a sociedade em rede; mas a sociedade também dispõe o dispositivo; e, por meio deste, a sociedade se põe em relação com a realidade e a dispõe - em uma relação complexa, interretroativa e indeterminada. Se o socius circula em rede, ele circula "disposto" em determinadas disposições; e essa circulação dispõe aquilo que emerge como dispositivo conexial observado. Os interagentes, contudo, não se sujeitam passivamente às configurações do dispositivo, mas, a partir de seus interesses e necessidades, efetuam também reações e resistências, que, por sua vez, dispõem o dispositivo em novas configurações.

É essa “configuração de configurações” sociais, tecnológicas e simbólicas que catalisam a midiatização digital da sociedade, possibilitando um maior aprofundamento, abrangência e aceleração dos processos midiáticos existentes em rede.

\section{Referências}

AGAMBEN, Giorgio. Che cos'è un dispositivo? Roma: Nottetempo, 2006.

BRAGA, José Luiz. Dispositivos interacionais. In: Anais do Encontro da Compós, 20, Porto

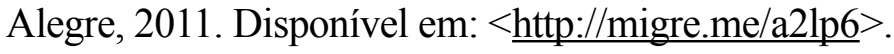

Dispositivos interacionais: lugar para dialogar e tensionar conhecimentos. Dispositiva, Belo Horizonte, v.1, n.1, mai./out. 2012c, p. 29-38.

O que a comunicação transforma? In: BRAGA, J. L. et al. (orgs.). Dez perguntas para a produção de conhecimento em comunicação. São Leopoldo, 2013, p. 156-171.

BRUNO, Fernanda. Mediação e interface: incursões tecnológicas nas fronteiras do corpo. In: SILVA, D. F. da; FRAGOSO, S. (org.). Comunicação na cibercultura. São Leopoldo: Editora Unisinos, 2001, p. 191-215.

CINGOLANI, Gastón. Sobre la distinción medio/dispositivo en Eliseo Verón. In: FAUSTO NETO, A. et.al. (orgs.). Relatos de investigaciones sobre mediatizaciones. Rosario: UNR Editora, 2015, p. 55-70.

FAUSTO NETO, Antonio. Midiatização, Prática Social - Prática de Sentido. In: Anais do Seminário sobre Midiatização, São Leopoldo, 2005.

. Como as linguagens afetam e são afetadas na circulação? In: BRAGA, J. L. et al. (orgs.). Dez perguntas para a produção de conhecimento em comunicação. São Leopoldo, 2013, p. 43-64. 
FERREIRA, Jairo. Uma abordagem triádica dos dispositivos midiáticos. Líbero, São Paulo, v. 9, n. 17, jun. 2006, p. 137-145.

- ¿Qué cultura se configura con los dispositivos digitales? Inferencias a partir de casos investigados desde el enfoque de la mediatización a partir de la Web 2.0. In: CEDAL. Cultura Digital en América Latina: investigación interuniversitaria Educación y Evangelización. Bogotá: CEDAL, 2012a, p. 250-269.

. Como a circulação direciona os dispositivos, indivíduos e instituições? In: BRAGA, J. L. et al. (orgs.). Dez perguntas para a produção de conhecimento em comunicação. São Leopoldo, 2013, p. 140-155.

FERREIRA, Jairo; DAIBERT, Paula. ¿Dónde estás? En búsqueda de lo tercero en el terreno de índices e íconos en el estúdio de un conflicto inexplorado: el caso sharek.al jazzera.com. In: CARLÓN, M.; FAUSTO NETO, A. (orgs.). Las políticas de los internautas. Buenos Aires: La Crujía, 2012, p. 81-96.

FOUCAULT, Michel. Sujeito e Poder. In: DREYFUS, H. \& RABINOW, P. Michel Foucault, uma trajetória filosófica: para além do estruturalismo e da hermenêutica. Rio de Janeiro: Universitária, 1995. p. 231-239.

. Os intelectuais e o poder - conversa entre Michel Foucault e Gilles Deleuze. In: FOUCAULT, M. Microfísica do poder. Rio de Janeiro: Graal, 2000, p. 69-78.

GALlOWAY, Alexander R. Protocol: How Control Exists After Descentralization. Cambridge: Massachusetts Institute of Technology Press, 2004.

KERCKHOVE, Derrick de. Connected Intelligence: The Arrival of the Web Society. Londres: Kogan Page, 1998.

LOTMAN, Iuri M. La semiosfera 1: semiótica de la cultura y del texto. Madrid: Ediciones Cátedra, 1996.

MORIN, Edgar. O método 3: o conhecimento do conhecimento. $2^{\mathrm{a}}$ ed. Porto Alegre: Sulina, 1999.

. O método 1: a natureza da natureza. $2^{\mathrm{a}}$ ed. Porto Alegre: Sulina, 2008.

MUSSO, Pierre. A filosofia da rede. In: PARENTE, A. (org.). Tramas da rede. Porto Alegre: Sulina, 2004, p. 17-38.

PERAYA, Daniel. O ciberespaço: um dispositivo de comunicação e de formação midiatizada. In: ALAVA, S. (org.). Ciberespaço e formações abertas: rumo a novas práticas educacionais? Porto Alegre: Artmed, 2002. p. 25-52. 
RODRIGUES, Adriano D. O paradigma comunicacional: história e teorias. Lisboa: Fundação Calouste Gulbenkian, 2011.

SBARDELOTTO, Moisés. "E o verbo se fez rede" uma análise da circulação do "católico" em redes comunicacionais online. 2016. 496 f. Tese (Doutorado em Ciências da Comunicação) -Programa de Pós-Graduação em Ciências da Comunicação, Universidade do Vale do Rio dos Sinos (UNISINOS), São Leopoldo, 2016. Disponível em: $<$ http://www.repositorio.jesuita.org.br/handle/UNISINOS/5366 $>$.

SODRÉ, Muniz. A ciência do comum: notas para o método comunicacional. Petrópolis: Vozes, 2014. 